PPPL-2827

PPPL-2827

UC-420

MEASUREMENT OF ION PROFILES IN TFTR NEUTRAL BEAMLINES

BY

J.H. KAMPERSCHROER, L.R. GRISHAM, H.W. KUGEL,

T.E. O'CONNOR, T.N. STEVENSON, A. VON HALLE, AND M.D. WILLIAMS

February 1992
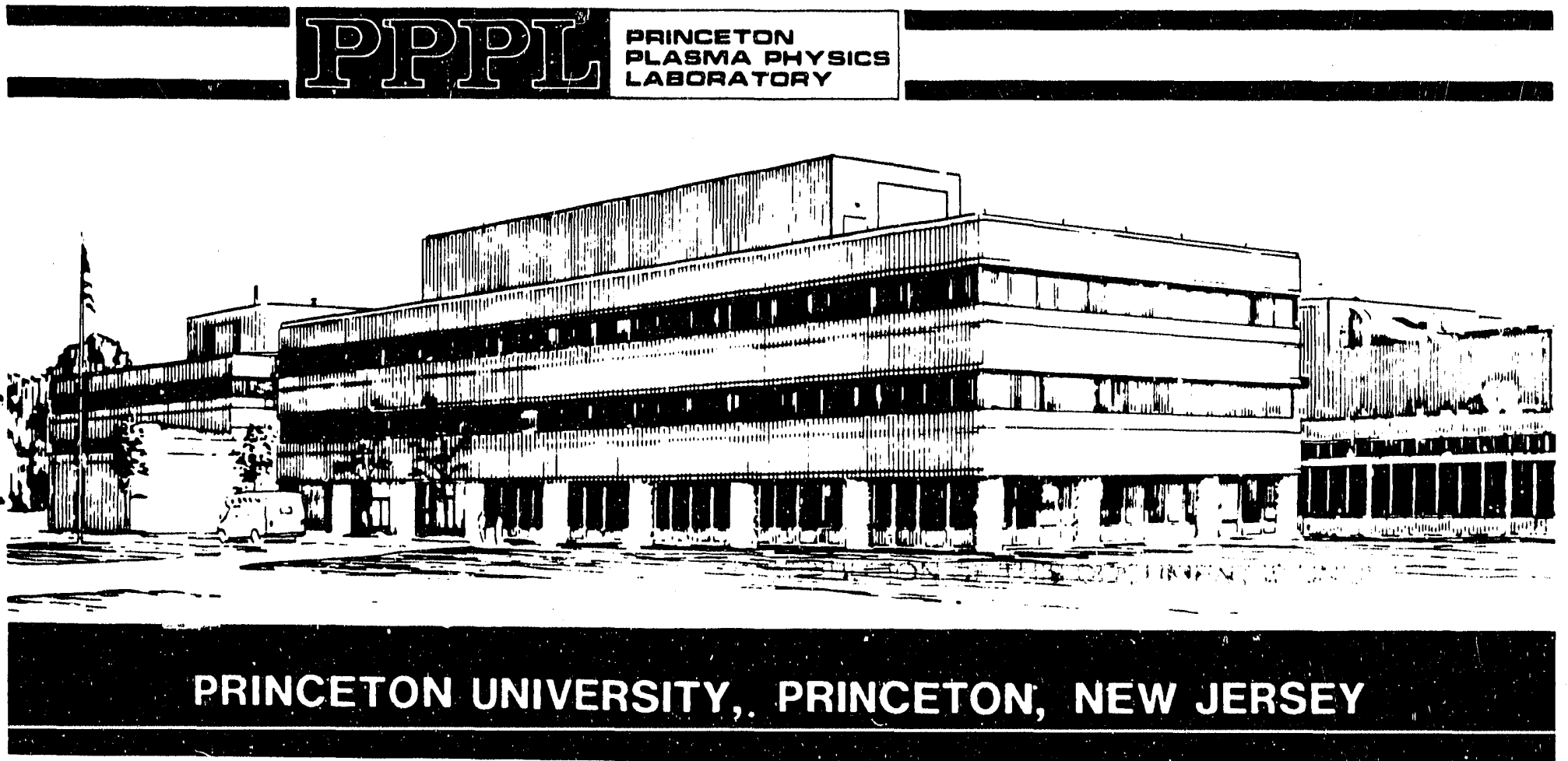


\section{NOTICE}

This report was prepared as an account of work sponsored by an agency of the United States Government. Neither the United States Government nor any agency thereof, nor any of their employees, makes any warranty, express or implied, or assumes any legal liability or responsibility for the accuracy, completeness, or usefulness of any information, apparatus, product, or process disciosed, or represents that its use would not infringe privately owned rights. Reference herein to any specific commercial produce, process, or service by trade name, trademark, manufacturer, or otherwise, does not necessarily constitute or imply its endorsement, recommendation, or favoring by the United States Government or any agency thereof. The views and opinions of authors expressed herein do not necessarily state or reflect those of the United States Government or any agency thereof.

\section{NOTICE}

This report has been reproduced directly from the best available copy.

Available to DOE and DOE contractors from the:

Office of Scientific and Technical Information

P.O. Box 62

Oak Ridge, TN 37831 ;

Prices available from (615) 576-8401.

Available to the public from the:

National Technical Information Service

U.S. Department of Commerce 5285 Port Royal Road Springfield, Virginia 22161

$703-487-4650$ 


\title{
Measurement of Ion Profiles in TFTR Neutral Beamlines
}

\author{
J. H. Kamperschroer, L. R. Grisham, H. W. Kugel, T. E. O'Connor, T. N. \\ Stevenson, A. von Halle, and M. D. Williams \\ Princeton Plasma Physics Laboratory, P O Box 451 Princeton, NJ 08543
}

\begin{abstract}
A technique is described whereby the ion dumps inside the TFTR Neutral Beam Test Stand were used to measure thermal profiles of the full-, half-, and thirdenergy ions. 136 thermocouples were installed on the full-energy ion dump, allowing full beam contours. Additional linear arrays across the widths of the half- and third-energy ion dumps provided a measure of the shape, in the direction parallel to the grid rails, of the half- and third-energy ions, and, hence, of the molecular ions extracted from the source. As a result of these measurements it was found that the magnet was more weakly focussing, by a factor of two, than expected, explaining past overheating of the full-energy ion dump. Hollow profiles on the half- and third-energy ion dumps were observed, suggesting that extraction of $\mathrm{D}_{2}{ }^{+}$and $\mathrm{D}_{3}{ }^{+}$are primarily from the edge of the ion source. If extraction of half-energy ions is from the edge of the accelerator, a divergence parallel to the grid rails of $0.6^{\circ} \pm 0.1^{\circ}$ results. It is postulated that a nonuniform gas profile near the accelerator is the cause of the hollow partialenergy ion profiles; the pressure being depressed over the accelerator by particles passing through this highly transparent structure. Primary electrons reaching the accelerator produce nonuniform densities of $\mathrm{D}_{2}{ }^{+}$through the ionization of this gas and $\mathrm{D}_{3}{ }^{+}$through $\mathrm{D}_{2}{ }^{+}$- gas collisions. A technique of rastering the ion beam
\end{abstract}


across the full-energy dump was examined as a means of reducing the power density. By unbalancing the current. in the two coils of the magnet, on a shot by shot basis, by up to a 2:1 ratio, it was possible to move the centerline of the fullenergy ion beam sideways by $\sim 12.5 \mathrm{~cm}$. The adoption of such a technique, with a ramp of the coil imbalance from 2:1 to 1:2 over a beam pulse, could reduce the power density ky a factor of $>1.5$. 


\section{INTRODUCTION}

Record levels of heating power, in excess of $33 \mathrm{MW}$, have been injected into the Tokamak Fusion Test Reactor (TFTR) using four neutral beamlines. ${ }^{1}$ In order to achieve this power, a total of $\sim 75 \mathrm{MW}$ of ions were extracted from twelve ion sources. Much can be learned about ion source operation through study of the 40 MW dissipated as unwanted power.

Positive ions exiting the neutralizer are deflected and separated, by a magnet, into constituent full-, half-, and third-energy $\mathrm{D}^{+}$, and deposited onto the ion dumps. Ion dumps on the TF'R Neutral Beam Test Stand ${ }^{2}$ (NBTS) were instrumented with thermocouples to measure heat deposition profiles. Since the magnet is a charged particle lens, the ion dump thermal profiles are images of the ion source, albeit with some smearing due to beam divergence. The magnet separates the full-, half-, and third-energy ions so that the profile of each can, in principle, be independently measured. To the extent that the divergences of the ions and neutrals are equivalent, the measured thermal profiles yield the shapes of the three neutral constituents of the beam.

In the usual model taken to compute beam power densities and transport, it is assumed that the beam is an array of spatially uniform emitters of gaussian (in angle) beamlets across the face of the ion source. ${ }^{3}$ Intensity distributions downstream are computed as a convolution of the contributions from each emitter. The imaging technique to be described provides a measure of the validity of the uniform extraction assumption.

At the nominal $104 \mathrm{kV}$ operating voltage at which $33 \mathrm{MW}$ injection was attained, the equilibrium neutral and positive ion fractions of the beam are 55\% and $44 \%$, respectively. However, less than $55 \%$ of the extracted vower is delivered to the calorimeter when the deflecting magnet is energized. The discrepancy is 
due to losses during transport of the beam from the inn source to the target. The computed scrape off on collimators, using the standard beam transport model and the measured beam divergence, accounts for only part of the measured loss, the remainder is anomalous. ${ }^{4}$ Results of the present experiment provide an explanation for some of the extra loss.

Power densities of $1.5 \mathrm{~kW} / \mathrm{cm}^{2}$ are predicted on the full-energy ion dump. ${ }^{5}$ Since all beam absorbing surfaces in the TFTR beamlines are inertially cooled, and the ion dumps must absorb power during the entire beam pulse (up to $2 \mathrm{~s}$ ), the ion dumps are one of the higher stressed components in the beamlines. It was not possible to significantly incline the full-energy ion dump to the incident beam to reduce power density. The angle of incidence on this dump is $30^{\circ}$, providing a power density reduction of two relative to normal incidence. Beam operation over the years has resulted in extensive thermal stress cracking on the full-energy ion dump, especially near the thermocouple plugs. An upgrade program has commenced in which all full-energy dumps will be replaced with a version with modified the thermocouple plugs.

A technique to reduce the average power density on ion dumps is to raster the beam during the pulse. ${ }^{6}$ Experiments have been performed on the NBTS to determine the feasibility of this technique.

\section{Experimental Apparatus and Techniques}

\section{A. Hardware}

Figure 1 is a plan view of the NBTS. (The test stand was disassembled in 1987. Power systems and instrumentation have been rededicated to the neutral beam systems in the tokamak test cell.) In order to accommodate three ion sources, the magnet assemblies have three gaps and the ion dumps are wide enough for three 
beams. Data to be discussed were obtained from operation of the central ion source only. Unless stated otherwise, the ion source for these experiments was the U. S. Common Long Pulse Ion Source developed by the Lawrence Berkeley Laboratory (LBL). ${ }^{7}$ The extraction area for the TFTR version of this ion source is $12 \mathrm{~cm}$ by $43 \mathrm{~cm}$. Grid rails span the $12 \mathrm{~cm}$ horizontal direction with ions accelerated in a vertical array of 43 beamlets.

Interest here lies primarily with the magnet and ion dump assemblies. The magnets are transmission-type with an upward deflection of $\sim 60^{\circ}$ for the fullenergy ions, $\sim 90^{\circ}$ for the half- energy ions, and $\sim 180^{\circ}$ for the third-energy ions. ${ }^{5}$ Figure 2 shows how each specie is directed to its own dump. Each dump is instrumented with thermocouples and water flow calorimetry. The $45^{\circ}$ entrance angle of the particles into the magnet, and the magnet's fringing field, ${ }^{8}$ produce a focussing force in the direction r, points (computed using the BEAM computer code) ${ }^{9}$ for each of the three ion species are indicated by the dots in figure 2. Focussing occurs in the direction perpendicular to the vertical bend plan (i.e., in the direction parallel to the ion source grid rails).

As viewed from the ion source, the magnetic field is directed from right to left. Wrapped around each pole is a current carrying coil. Yokes at the top and bottom of the magnet gap return the flux; field clamps beyond the coil limit the fringe field..$^{5}$

The full-energy ion dump is a curved, 2 inch thick copper plate. ${ }^{5}$ Both the halfand third-energy dumps are flat, 0.75 inch thick copper plates. ${ }^{5}$ All three had type $\mathrm{E}$ thermocouples embedded at the mid-point of cylindrical copper plugs, which were peened into holes drilled through the ion dumps. ${ }^{10}$ 
An array of 136 thermocouples, with a six wide by twelve tall central array, was installed on the full-energy dump. Spacing for the central array was $10 \mathrm{~cm}$ in the vertical direction and $5 \mathrm{~cm}$ horizontally. Figure 3 is a photograph of the full-energy dump, with the thermocouple array evident; a portion of the halfenergy dump visible at the top of the assembly. The central part of the full-energy ion dump, with numerous thermocouple plugs, is the target area for the central ion source. Cracks emanating from the thermocouple plugs along the centerline of the dump are also evident. Those portions of the dump devoted to the outer two ion sources were minimally instrumented. Data from those few thermocouples were incorporated into the contouring algorithm for the central ion source, bringing the total number of thermocouples contoured to 136 .

For the half-energy dump, the thermocouple array was seven in the bend plane and three wide, with a spacing of $10 \mathrm{~cm}$ in both directions. At the location where the central trajectory of the half-energy ion beam intersected the dump, a linear ten wide thermocouple array with a spacing of $5 \mathrm{~cm}$ was installed in the direction perpendicular to the bend plane. The third-energy dump had a linear array of eleven thermocouples in the bend plane, crossed, at a point $70 \mathrm{~cm}$ above the bottom of the dump, by a linear array of seven thermocouples. Spacing was 10 $\mathrm{cm}$ for the eleven thermocouples. Spacing for the seven thermocouples was 4.5 $\mathrm{cm}$ for the central three and $9 \mathrm{~cm}$ for the outer two on each side. Figure 4 is a photograph of this ion dump. The crossed array is evident between the four large pumping holes. Above, and perpendicular to, the third-energy dump is the halfenergy dump, part of which can be seen in the figure.

Instrumentation and acquisition of the thermocouples was through the CICADA computer system which has been described elsewhere. ${ }^{11}$ 


\section{B. Software}

Isothermal contours were computed from the thermocouple temperature rise data taken from the full-energy ion dump thermocouples. ${ }^{12}$ These contours were interpolated between thermocouples to an accuracy of approximately $2 \mathrm{~cm}$ on the central array. Contouring of the half- and third-energy ion dump data was not carried out. For these ion dumps, data were obtained from the linear arrays of thermocouples in the direction perpendicular to the bend plane of the magnet.

Computation of the charged particle trajectories through the magnet were carried with the computer code BEAM. ${ }^{9}$ Comparison will be made between the measured shapes of the full-energy ion beam and those predicted by BEAM.

\section{Beam optics}

Given a test particle's starting location $x_{0}$ and angle $x_{0}$ ' in the phase space of the ion source, its location $x$ and angle $x^{\prime}$ at a point beyond the magnet are given by

$$
\begin{aligned}
{\left[\begin{array}{l}
x \\
x^{\prime}
\end{array}\right] } & =\left[\begin{array}{ll}
1 & L_{2} \\
0 & 1
\end{array}\right]\left[\begin{array}{ll}
M_{11} & M_{12} \\
M_{21} & M_{22}
\end{array}\right]\left[\begin{array}{ll}
1 & L_{1} \\
0 & 1
\end{array}\right]\left[\begin{array}{l}
x_{0} \\
x_{0}^{\prime}
\end{array}\right] \\
& =\left[\begin{array}{ll}
m_{11} & m_{12} \\
m_{21} & m_{22}
\end{array}\right]\left[\begin{array}{l}
x_{0} \\
x_{0}^{\prime}
\end{array}\right]
\end{aligned}
$$

The ' $M$ ' matrix, describing passage through the magnet, is computed by BEAM. The other two matrices in the top line are for drift spaces of length $L_{1}$ and $L_{2}$, leading up to and following the magnet, respectively; the ' $m$ ' matrix is the composite transfer matrix describing transport from the ion source to a distance $\mathrm{L}_{2}$ beyond the magnet. At the point where the central trajectory of the full-energy 
ion beam intersects the ion dump, the ' $m$ ' matrix in the direction perpendicular to the bend plane is $\mathrm{m}_{11}, \mathrm{~m}_{12}, \mathrm{~m}_{21}, \mathrm{~m}_{22}=-3.94,-1198 \mathrm{~cm},-2.26 \times 10^{-2} \mathrm{~cm}^{-1},-7.08$. For the half-, and third-energy ions, the matrix elements are $-3.90,-1310 \mathrm{~cm}$, $-2.57 \times 10^{-2} \mathrm{~cm}^{-1},-8.90$ and $-0.794,-303 \mathrm{~cm},-3.18 \times 10^{-3} \mathrm{~cm}^{-1},-2.47$, respectively. Magnifications for the full- and half-energy ion dumps, as given by the $m_{11}$ matrix element, are $\sim-3.9$. The negative value is implies a left to right reversal of the image. These magnifications are approximately what is expected from the locations of the focal points giver, in figure 2. (Magnification is approximately equal to the distance from the focal point to the the ion dump divided by the distance from the focal point to the magnet entrance.)

Power densities are computed by integrating, in phase space, over all source locations which communicate to the desired point downstream and taking the derivative of the result. If a spatially uniform emitter with a gaussian spread in angle is assumed, the following power density as a function of position results:

$$
\begin{aligned}
P= & \frac{P_{0} \sin \theta}{16 m_{11} x_{0} y_{0}} \cdot\left[\operatorname{erf}\left(\frac{x+m_{11} x_{0}}{m_{12} x_{0}{ }^{\prime}}\right)-\operatorname{erf}\left(\frac{x-m_{11} x_{0}}{m_{12} x_{0}{ }^{\prime}}\right)\right] \\
& {\left[\operatorname{erf}\left(\frac{y+y_{0}}{z y_{0}{ }^{\prime}}\right)-\operatorname{erf}\left(\frac{y-y_{0}}{z y_{0}{ }^{\prime}}\right)\right] . }
\end{aligned}
$$

$P_{0}$ is the incident power, $\theta$ is the angle at which the ions intersect the ion dump, $x_{0}$ is the half-width of the ion source, $x_{0}{ }^{\prime}$ is the arctangent of the $1 / e$ halfdivergence in the $x$-direction, $y_{0}$ is the source half-height, $y_{0}{ }^{\prime}$ is the arctangent of the $1 / \mathrm{e}$ half-divergence in the $\mathrm{y}$-direction, $\mathrm{x}$ and $\mathrm{y}$ are the distances orthogonal to the beam axis, and $\mathrm{z}$ is the distance from the ion source to the point in question. 


\section{Results}

\section{A. Ion dump profiles}

Isotherms of the full-energy ion dump for beam operation of $57 \mathrm{~A}$ at $102 \mathrm{kV}$ for $2 \mathrm{~s}$ are shown in figure 5 . The peak temperature rise was $66.7^{\circ} \mathrm{C}$; isotherms are plotted at $80,60,40$, and $20 \%$ of this value. A contour island to the left of center is due to an erroneous thermocouple reading. Thurmocouple locations are indicated by dots. The contours are approximately equally spaced in the horizontal plane, implying a triangular shape in this direction. Contours are smooth to one-half of the thermocouple spacing, or $\pm 2.5 \mathrm{~cm}$. Not all of the full-energy ions are captured on the full-energy dump, some spill over onto the half-energy ion dump at the top.

A profile, for the same shot, across the ter thermocouple half-energy ion dump linear array is shown in figure 6. A distinct depression in the center of this profile, in the direction perpendicular to the bend plane, is evident. Thermocouples in the 7 by 3 array also show hollowness, but with cruder resolution than the ten wide linear array. There is no evidence in the data from the 7 by 3 array to indicate the presence of a power density peak in the direction of the bend plane.

A photograph of the third-energy ion dump after disassembly of the test stand has been shown in figure 4. A ' $\mathrm{V}$ '-shaped area of the dump has been sputtered clean. This wear occurred over the lifetime of this ion dump, so it cannot be claimed, based on this photo alone, that such an ion profile resulted on the shot in figure 6. Figure 7, taken on the san e shot as figure 6, does support a hollow profile across the width of the third-energy dump. Thermocouples corresponding to the peak temperature rises in figure 7 are those falling on the sputtered ' $\mathrm{V}$ ' in figure 4 . 
An experiment was carried out in which the ion source gas efficiency was varied from $64 \%$ to $41 \%$ by changing the gas throughput into the ion source from 13 torr-1/s to 21 torr- $1 / \mathrm{s}$ at fixed beam current. ${ }^{13}$ Beam conditions during this scan were $61 \mathrm{~A}$ of ions extracted at $99 \mathrm{kV}$ for $0.5 \mathrm{sec}$. Half-energy ion profiles are given in figure 8. At high gais efficiency (solid line), the hollowness of the half-energy ion profile is enhanced with a possible shift of the peaks away from each other.

In an additional experiment, the perveance of the ion source was varied from $1.47 \mu$ perv to $1.89 \mu$ perv. This experiment was carried out at $95 \mathrm{kV}$ with a pulse length of $1.5 \mathrm{~s}$. Figure 9 is a plot of a half-energy ion dump hollowness parameter versus perveance. The hollowness parameter is the ratio of the pea.s temperature rise on the left-hand peak of the thermal profile to the lowest temperature in the center. As optimum perveance, $1.83 \mu$ perv, was approached from lower values, the profile became nore hollow. It cannot be ascertained whether there was a hollowness decrease after optimum perveance was exceeded, since the scan was not carried sufficiently overdense.

\section{B. Rastering}

Rastering of the beam across the full-energy ion dump was achieved by unbalancing the current in the two coils of the magnet. Current through the lefthand coil (viewed from the ion source) was reduced by placing unused coils on other magnets of the beamline in series/parallel combinations with it. Power supply current was increased to maintain a constant total ampere-turns. A maximum imbalance, ratio of the right-hand coil current to left-hand coil current, of 2:1 was attained. Data were taken at imbalances of 1.25, 1.5 and 2 . Dynamic rastering was not carried out; coil imbalance was varied on a shot-byshot basis. 
Figure 10 shows a thermal profile of the full-energy ion dump obtained during a $2: 1$ imbalance. Beam parameters were $27 \mathrm{~A}$ at $72 \mathrm{kV}$ for $0.5 \mathrm{~s}$ using an LBL short pulse ion source. ${ }^{14}$ Contours are plotted as viewed from the ion source, implying a shift to the left. The magnitude of the shift of the vertical centerline of the profile is $12.5 \mathrm{~cm}$, or approximately the half width of the profile. (A vertical line in figure 10 indicates the centerline of the thermocouple array.) Shift magnitude as a function of imbalance is plotted in figure 11. An approximately linear relationship between imbalance and shift is noted.

\section{Discussion}

\section{A. Fullenergy ions}

With the aid of equation 2 , the expected full-energy ion footprint on the ion dump can be calculated. 1/e half-width divergences of $0.4^{\circ} \times 1.05^{\circ}$ (parallel and perpendicular to the grid rails, respectively), as calculated from a least squares fit to 60 thermocouples located on the beamline calorimeter, ${ }^{12}$ will be used. Results of the calculation are given in figure 12. There is a widening of the profile at the top of the dump due to the fact that the focal point of the magnet is near the magnet; ions striking the top of the ion dump travel farther, on average, from the focal point to reach the dump than do those striking the bottom.

Comparison of figure 12 , the predicted profile, with figure 5 , the measured profile, reveals several major differences. First, the measured profile is narrower than predicted. Given the calculated magnification of 3.9, the edges of a nondivergent beam should be $48 \mathrm{~cm}$ apart, considerably farther apart than the $\sim 20 \mathrm{~cm}$ measured. Magnification is not the predicted 3.9, but rather a value closer to 2 . Second, the measured profile is more peaked than calculated, not exhibiting the high plateau of figure 12. From this observation we are tempted to conclude that 
extraction of $\mathrm{D}^{+}$is peaked near the center of the ion source, not uniform as predicted.

\section{B. Halfenergy ions}

From figure 6 we deduce that the magnification for the half-energy ions is 1.7. This comes from the assumption that the peaks of the profile represent the edges of the $12 \mathrm{~cm}$ wide ion source, and that the measured distance between the two peaks is $20 \mathrm{~cm}$. As with the full-energy ions, the predicted magnification is in er:or by approximately a factor of two. In this case the difference can be well quantified, given the assumption of edge extraction.

Ion beam imaging allows determination of the divergence of each ion specie. Such a determination is predicated upon knowledge of the uniformity of extraction. For the case of the fractional energy ions at hand, the divergence calculation is simplified by the assumption of extraction from two line sources, one at either edge of the ion source. The 1/e half-widths of the two peaks yield a divergence of $0.6^{\circ} \pm 0.1^{\circ}$ for the half-energy ion beam. Such a value is in agreement with values deduced from published OMA divergences of the fullenergy component and the total beam ${ }^{15}$ and from mass resolved charge exchange analyzer and Rutherford backscattering measurements. ${ }^{2}$ For comparison, the full-energy ion divergence is somewhat less than that of the composite neutral beam, namely $0.4^{\circ}$, as measured on the calorimeter. Reasonable partial-energy ion divergences result from the model of edge extraction, giving credence to the model.

A line source model for the extraction of the molecular ions is proposed. Two gaussian distributions, one at each edge of the ion source is assumed yielding the following beam intensity distribution: 


$$
f(x)=\frac{1}{2 x_{e} \sqrt{\pi}}\left\{\exp \left[-\left(\frac{x-x_{0}}{x_{e}}\right)^{2}\right]+\exp \left[-\left(\frac{x+x_{0}}{x_{e}}\right)^{2}\right)\right\}
$$

$X_{e}$ is the e-folding width at a distance $z$ frow the ion source $\left(x_{e}=z \tan \theta_{e}\right), \theta_{e}$ being the divergence, and $x_{0}$ the source half-width. For the case of $\theta_{e}=0.6^{\circ}, x_{0}=6 \mathrm{~cm}$, the distributions in figure 13 are computed at distances of $100 \mathrm{~cm}, 500 \mathrm{~cm}$ (location of the ion dumps), and $1100 \mathrm{~cm}$ (location of the TFTR plasma) from the ion source. The distribution at $500 \mathrm{~cm}$ matches that of the thermal footprint on the halfenergy ion dump (not including magnification). As the beam propagates down the beamline, such that $x_{e}>x_{0}$, the distribution filis in and becomes more gaussian.

\section{Third energy ions}

The behavior of $\mathrm{D}_{3}{ }^{+}$is similar to that $0 \mathrm{\prime}_{2} \mathrm{\prime}_{2}^{+}$. Bifurcation of the thermal profile implies that the $\mathrm{D}_{3}{ }^{+}$is extracted prima cily from the edge of the ion source. Divergence is again $\sim 0.6^{\circ}$. Due to the relative coarseness of this dump's thermocouple array to the size of the thermal profile, $0.6^{\circ}$ is the upper limit to the divergence. The fact that the ' $V$ '-shape is open at the top indicates that molecular ions are extracted from the edge of the accelerator left and right, but not top and bottom. But, due to the limited data, it cannot be stated that this is actually the case.

Only a crude estimate can be made for the magnification. At the point where the third-energy beam intersects the dump (about $20 \%$ of the way up from the bottom) the predicted magnification is $\sim-0.8$. The separation between the two 
peaks :hould be about $10 \mathrm{~cm}$. From figure 4 it can be seen that the actual value is considerable less. At the beam centerline intersection point, the separation between the two sputtered lines is no more than $5 \mathrm{~cm}$. (Figure 7 cannot be used since the location of the linear thermocouple array is well above the third-energy beam centerline/ion dump intersection point.) As was the case with the full- and half-energy ions, the magnification differs from the predicted value by approximately a factor of two.

More cari be deduced about the magnet's focal properties from the shape of the sputtered area in figure 4. The focal point is at the very bottom of the ion dump, at the apex of the sputtered ' $\mathrm{V}$ '. From figure 2, which gives the predicted location of the focal point, it is evident that the focal length is approximately twice as long as expected, in agreement with the magnification estimate above.

The fact that the magnification is different than expected explains some of the difficulties experienced with the full-energy ion dumps. By moving the focal point closer to the ion dump, the power density is a factor of two greater than anticipated.

\section{Beam transport}

If ions are not extracted uniformily from the ion source, then transport of the beam is more cornplicated than previously assumed. Beam loss on one side of a scraper is given by the integral of the power distribution function from $x=x_{1}$, the half-width of the scraper, to infinity. Total loss for a scraper with an opening of $2 \mathrm{x}_{1}$, and the distribution function in equation 3 , is:

$$
1-\frac{1}{2}\left[\operatorname{erf}\left(\frac{x_{1}+x_{0}}{x_{e}}\right)+\operatorname{erf}\left(\frac{x_{1}-x_{0}}{x_{e}}\right)\right]
$$


For the case in question, namely $\theta_{\mathrm{e}}=0.6^{\circ}$ and $\mathrm{x}_{0}=6 \mathrm{~cm}$, the loss in traversing the magnet scraper is $\sim 25 \%$. This scraper is $330 \mathrm{~cm}$ downstream of the ion source and is $15 \mathrm{~cm}$ wide. Losses are greatest near the ion source where the hollowness of the profile is most pronounced. In the far field, the ion source looks like a point source even for hollow extraction. Transport of full-energy ions through the magnet scraper is nearly lossless; in part because of the different extraction distribution, but also because of its smaller divergence $\left(0.4^{\circ}\right)$.

The hollowness of the partial-energy components does not dramatically alter the transport of the beam as a whole to the tokamak, but it does significantly affect the relative transport of the three components. About $20 \%$ of the total power extracted from the ion source is in the form of molecular ions. Loss of $25 \%$ of this is equivalent to $5 \%$ of the total power. Folding in the neutralization efficiencies of the three beam components, the loss is $8 \%$ of the injected power. Since the neutral power measurement is based upon power delivered to the beamline calorimeter, which is well behind the magnet scraper, the power calculation is unaffected by this discovery. The loss is included in the power calibration.

The losses predicted with this new model for the molecular ions accounts for a large fraction of the anomalous loss observed in the past. Significant losses have been observed on TFTR beamlines on components close to the ion source, ${ }^{16}$ as first noted by Berkner et al. ${ }^{4}$ A model similar to that proposed here has been empirically deduced by Kim and Stewart to model losses inside the DIII-D neutral beam injectors. ${ }^{17}$ Their distribution of a gaussian with a bump on the tail could have arisen from non-uniform extraction.

\section{Beam species}

Because of the different losses for each neutral beam component, the beam composition inferred from neutralizer OMA diagnostic and projected 
downstream to TFTR is incorrect. Greater losses for half- and third-energy neutrals than for the full-energy neutrals yields a relative full-energy particle flux, at TFTR; larger than quoted. For nominal beamline operating conditions, i.e., $>100 \mathrm{kV}$ and an extracted beam composition of $80 \% \mathrm{D}^{+}, 10 \% \mathrm{D}_{2}{ }^{+}$, and $10 \%$ $\mathrm{D}_{3}{ }^{+}$, the relative full-energy neutral flux at the tokamak is $10 \%$ to $15 \%$ greater than stated. This phenomenon was observed previously on the NBTS when a comparison was made with OMA measurements in both the neutralizer and in the duct between the beamline and the target chamber. ${ }^{2}$

\section{E. Rastering}

It has been shown that full-energy ions can be moved sideways (rastered) on the ion dump enough to reduce the average power density by a factor of $>1.5$. Implementation of this technique would require ramping of the magnet current from an imbalance of $2: 1$ to the left to an imbalance of 2:1 to the right over a beam pulse. A 2:1 imbalance is at the upper limit considered, since any further shift would begin to introduce overlap of the beam footprint onto locations previously vacated by other ion sources. Ions do not strike the pole faces or field clamps of the magnet during rastering because of beam narrowing due to the focal properties of the magnet.

Application of this technique to TFTR beamlines would require the purchase of a power supply dedicated to each coil. The current rating of these supplies would need to be $1100 \mathrm{~A}$ in order to operate with $120 \mathrm{kV}$ tritium and accommodate a 2:1 imbalance.

Inductive effects do not limit the time response of the field inside the magnets. Dynamic factors would not be expected to pose a problem, but would need to be thoroughly examined before implementation. 


\section{F. Non-uniformity model}

There are at least two mechanisms capable of creating the type of plasma nonuniformity observed. First, workers at the Japan Atomic Energy Research Institute (JAERI) have measured, under non-ideal conditions, nonuniform plasma profiles using Langmuir probes. ${ }^{18}$ Their explanation of this phenomenon was a nonuniform distribution of primary electrons caused by perturbations of the source's magnetic field. Such is not believed to be the case with the US common long pulse ion sources which were probed in a similar manner while under development; ${ }^{19}$ nonuniformities of the type under discussion were not observed. Extraction from an ion source with a spatially varying plasma density would result in perveance mismatch across the accelerator, and resultant varying divergence. Here, the full-energy ions dominate in the center of the ion source and partial energy ions are predominate near the edge.

Second, there is the possibility of a nonuniform gas density in the presence of a uniform primary electron distribution. Such is believed to be the case here. While the total plasma density is relatively uniform across the extraction plane, the relative composition of the three ionic species is not. The $20 \%$ of the ionic current being carried by molecular ions appears to be coming from the peripheral $\sim 20 \%$ of the extraction area (of order one centimeter out of a $12 \mathrm{~cm}$ wide ion accelerator).

The nonuniform gas density is created at the accelerator. Plasma in the ion source is confined by permanent magnets on the back and sides, ${ }^{19}$ but is free to drift toward the accelerator. The inside dimensions of the plasma generator are $26 \mathrm{~cm}$ by $65 \mathrm{~cm}$, values considerably larger than the $12 \mathrm{~cm} \mathrm{x} 43 \mathrm{~cm}$ extraction area. Ions striking the accelerator grids or the accelerator defining mask recombine to form $\mathrm{D}_{2} \cdot{ }^{20}$ Gas atoms and molecules directed toward the accelerator also impinge upon either the mask or accelerator and are redistributed. Gas 
density is greatest near the edge of the accelerator because the accelerator structure is $60 \%$ transparent and a fraction of the gas striking the shaped source grid can escape on a forward directed bounce. Gas molecules at the edge are retained. An estimate of the gas density ratio between the edge and center of the accelerator is 3:1. (An ion or gas molecule directed toward the accelerator has a > $60 \%$ chance of getting through.)

Given such a gas density distribution, it is not yet well understood how the gas can be ionized with a mean free path of order $1 \mathrm{~cm}$. The electron temperature and density, and especially the behavior of the primary electrons are not well known for the long pulse ion source. Estimates made for the mean free path of gas molecules in the TFTR short pulse ion sources were of the order of the dimensions of the ion source (tens of $\mathrm{cm}$ ). ${ }^{21}$ Given the confining magnetic fields of the long pulse sources, the mean free path for neutrals is now shorter. What is known for a certainty is that efforts to create ion sources with high $\mathrm{D}^{+}$fraction have gone to great lengths to limit the presence of primary electrons from the vicinity of the accelerator. ${ }^{22-25}$ The key to improving the extracted $\mathrm{D}^{+}$fraction of the beam and to eliminating the nonuriform species effect is understanding and controlling the trajectories of the primary electrons.

The method of injecting gas into the TFTR ion sources was recently changed from feeding it all into the ion source, as was done in these experiments. Present operation injects $\sim 5$ torr-1/s of gas into the ion source with a larger amount $(\sim 15$ torr $-1 / \mathrm{s}$ ) added to the center of the neutralizer. ${ }^{26}$ This technique was adopted to ensure that there is always sufficient neutralizer gas density. The quantity of gas injected into the ion source is sufficient to supply the flux of extracted ions. Some of the gas injected directly into the neutralizer flows directly into the beamline and some flows towards the ion source. Gas from the neutralizer enters the ion source through the grids. If the $\sim 5$ torr- $1 / \mathrm{s}$ injected into the ion source is sufficient 
to supply all the beam particles, approximately the same number of molecules must exit the accelerator as enter from the neutralizer. This will have the effect of reducing the gas density nonuniformity across the extraction plane, but not eliminating it.

For tritium beam operation, the plan is to inject all the gas into the neutralizer, none directly into the ion source. ${ }^{26,27}$ This modification is being planned to keep the gas injection system at ground notential, avoiding piping tritium into the $\mathrm{SF}_{6}$ filled source enclosure and simplifying the electronic interface. To study likely hollow molecular ion extraction with this and the present gas injecticn scheme, it is proposed to add cross thermocouple arrays on the ion dumps in one of the heating beamlines. OMA measurements in the duct are also planned. These measurements should ascertain the present and future hollowness of the partial-energy beam profiles.

\section{ACKNOWLEDGEMENTS}

The authors would like to thank: the Lawrence Berkeley Laboratory for copiously instrumenting the prototype ion dump with thermocouples; Ben Pritchard, Jr. for agreeing to further instrument the full-energy ion dump with thermocouples; Vic Garzotto and John Desandro for fabricating and installing extra thermocouples beyond those supplied by LBL; Harold Eubank for bringing the idea of rastering the beam on the ion dump to their attention; John Edwards for shunting the magnet current during the rastering experiment and for operation of the ion source during many of the experiments; Mark Cropper for installation and operation of the instrumentation and vacuum system and for operational assistance; the rest of the TFTR neutral beam operations team without whose assistance the beams would never run; Paras Shah, Raj Mukherji, 
and Ed Theil for the thermocouple software; Jerry Johnson for his assistance with the instrumentation; Bill Cooper for loan of the BEAM code output; Kelley Dagenhart for discussions on beam rastering; and to Klaus Halbach for teaching one of us (JHK) how to compute beam power density and transmission via the techniques described. This work was supported by the U. S. Department of Energy under contract DE-AC02-CHO-3073. 
REFERENCES

${ }^{1}$ T. Stevenson, J. Kamperschroer, L. Dudek, L. Grisham, R. Newman, T. O'Connor, A. von Halle, and M. D. Williams, to be published in Proceedings of the Fourteenth Symposium on Fusion Engineering, San Diego, 1991.

${ }^{2}$ H. W. Kugel, G. M. Gammel, L. R. Grisham, R. Kaita, J. H. Kamperschroer, R.

A. Langley, C. W. Magee, S. S. Medley, T. J. Murphy, A. L. Roquemore, and M.

D. Williams, Rev. Sci. Instrum 60, 37 (1989).

${ }^{3} \mathrm{~J}$. Kim and J. H. Whealton, Nucl. Instrum. and Meth. 141, 187 (1977).

${ }^{4}$ K. H. Berkner, J. H. Feist, V. L. Jacobson, A. F. Lietzke, J. W. Roberts, R. R. Smith, A. Wekhof, and J. E. Willis, in Proceedirigs of the Ninth Symposium on Engineering Problems of Fusion Research, Chicago, 1981 (IEEE, New York, 1981), Vol. 1, p. 763.

${ }^{5}$ L. C. Pittenger, L. E. Valby, R. R. Stone, L. R. Pedrotti, B. Denhoy, and R. Yoard, in Proceedings of the Eighth Symposium on Engineering Problems of Fusion Research, San Francisco, 1979 (IEEE, New York, 1979), Vol. 2, p. 831.

${ }^{6}$ W. K. Dagenhart and T. C. Tucker, J. Appl. Phys. 56, 22 (1984).

${ }^{7}$ M. C. Vella, W. S. Cooper, P. A. Pincosy, R. V. Pyle, P. D. Weber, and R. P. Wells, Rev. Sci. Instrum. 59, 2357 (1988).

${ }^{8}$ K. Lou, D. Roth, J. Haughian, R. Nemetz, G. Newell, R. Byrns, and A. Roberts, in Proceedings of the Eighth Symposium on Engineering Problems of Fusion Research, San Francisco, 1979 (IEEE, New York, 1979), Vol. 2, p. 967.

${ }^{9} \mathrm{BEAM}$ was the product of, and $x$ an for the TFTR beamline, by Klaus Halbach of the Lawrence Berkeley Laboratory.

10The thermocouple plug concept was inherited from LBL (drawing 19Q0154). 
11J. McEnerney, N. Arnold, G. Christianson, J. Chu, H. K. Feng, J. George, G. Johnson, J. Kamperschroer, H. Kugel, R. Lautenbacher, J. Montague, P. Mukherji, T. O'Connor, W. Rauch, J. Schobert, R. Segers, P. Shah, W. Stark, and M. Williams, in Proceedings of the Eleventh Symposium on Fusion Enginesring, Austin, 1985 (IEEE, New York, 1986), Vol. 1, p. 301.

${ }^{12}$ C. F. Burrell, W. S. Cooper, W. F. Steele, and R. R. Smith, in Proceedings of the Seventh Symposium on Engineering Problems of Fusion Research, Knoxville, 1977 (IEEE, New York, 1977), Vol. 1 , p. 374.

${ }^{13}$ J. H. Kamperschroer, G. M. Gammel, H. W. Kugel, L. R. Grisham, T. N. Stevenson, A. von Halle, and M. D. Williams, J. Vac. Sci. Technol. A 7, 8ł, 1989. ${ }^{14}$ K. H. Berkner, C. F. Burrell, W. S. Cooper, K. W. Ehlers, A. F. Lietzke, H. M. Owren, J. A. Paterson, R. V. Pyle, and J. W. Stearns, in Proceedings of the Eighth Symposium on the Engineering Problems of Fusion Research, San Francisco, 1979 (IEEE, New York, 1979), Vol. 1, p. 214.

${ }^{15}$ P. D. Weber, H. M. Owren, J. A. Paterson, P. A. Pincosy, R. V. Pyle, R. P. Wells, and M. C. Vella, Rev. Sci. Instrum. C7, 2714 (1986).

${ }^{16}$ J. H. Kamperschroer, L. R. Grisham, L. E. Dudek, F. M. Gammel, G. A. Johnson, H. W. Kugel, L. Lagin, T. E. O'Connor, P. A. Shah, P. Sichta, T. N. Stevenson, A. von Halle. M. D. Williams, and R. Bastasz, Rev. Sci. Instrum. 60, 3377 (1989).

17J. Kim and L. D. Stewart, Fusion Technol. 8, 1717 (1985).

${ }^{18}$ S. Tanaka, M. Akiba, H. Horiike, M. Matsuoka, Y. Ohara, and Y. Okumura, Rev. Sci. Instrum. 57, 145 (1986).

${ }^{19}$ P. A. Pincosy, K. W. Ehlers, A. F. Lietzke, H. W. Owren, J. A. Paterson, R. V. Pyle, and M. C. Vella, Rev. Sci. Instrum. 57, 2705 (1986).

20J. Kim and R. C. Davis, Appl. Phys. Lett. 30, 130 (1977).

${ }^{21}$ C. F. Chan, C. F. Burrell, and W. S. Cooper, J. Appl. Phys. 54, 6119 (1983).

${ }^{22} \mathrm{~K}$. W. Ehlers and K. N. Leung, Rev. Sci. Instrum. 52, 1452 (1981). 
${ }^{23}$ T. S. Green, J. R. Coupland, D. P. Hammond, A. J. T. Holmes, A. R. Martin, R. S. Hemsworth, and E. Thompson, in Proceedings of the Tenth International Conference on Plasma Physics and Controlled Nuclear Fusion Research, London, 1984 (IAEA, Vienna, 1985), Vol. 3, p. 319.

${ }^{24}$ K. Watanabe, M. Araki, M. Dairaku, H. Horike, Y. Ohara, Y. Okumura, J. Pamela, S. Tanaka, and K. Yokoyama, Rev. Sci. Instrim. 62, 2142 (1991).

${ }^{25}$ K. Watanabe, M. Araki, M. Dairaku, H. Horiike, Y. Ohara, Y. Okumura, S. Tanaka, and K. Yokoyama, Rev. Sci. Instrum. 61, 1694 (1990).

26 J. H. Kamperschroer, L. E. Dudek, L. R. Grisham, R. A. Newman, T. E. O'Connor, T. N. Stevenson, A. von Halle, M. D. Williams, and K. E. Wright, Rev. Sci. Instrum. 62, 1964 (1991).

${ }^{27}$ L. R. Grisham, H. F. Dylla, M. D. Williarns, K. Wright, and R. Causey, J. Vac. Sci. Technol. A 7, 944 (1989). 


\section{FIGURE CAPTIONS}

Figure 1. Schematic plan view of the TFTR Neutral Beam Test Stand.

Figure 2. Schematic elevation view of the deflection magnet and ion dump assemblies. Trajectories of the central rays of the full-, half-, and third-energy $\mathrm{D}^{+}$are shown. Dots on the trajectories indicate the predicted focal points.

Figure 3. Photograph of the ion dump assembly showing the full-energy dump and part of the half-energy dump at the top.

Figure 4. Photograph of the ion dump assembly showing the third-energy dump and part of the half-energy dump at the top.

Figure 5. Isotherms on the full-energy ion dump. Peak $\Delta \mathrm{T}$ was $66.7^{\circ} \mathrm{C}$; isotherms are at $80,60,40$, and $20 \%$ of this value.

Figure 6. Thermal profile across the ten thermocouple linear array spanning the width of the half-energy ion dump. Data is from the same shot as figure 5 .

Figure 7. Thermal profile across the seven thermocouple array spanning the width of the third-energy ion dump. Data is from the same shot as figure 5 and 6. 
Figure 8. Thermal profiles across the ten thermocouple array spanning the width of the half-energy ion dump. Solid line is for a gas throughput of 13 torr-1/s into the ion source and the dotted line is for 21 torr-1/s.

Figure 9. Half-energy beam hollowness (ratio of left-hand peak temperature to minimum temperature in the valley) versus perveance in micro-pervs $\left(10^{-6} \mathrm{~V}^{3 / 2} / \mathrm{A}\right)$.

Figure 10. Full-energy isotherms, as in figure 5, for a $2: 1$ imbalance in the two coils of the magnet. Peak temperature rise is $2{ }^{\circ} \mathrm{C}$.

Figure 11. Sideways displacement of the full-energy beam centerline as a function of coil imbalance.

Figure 12. Predicted full-energy ion beam isotherms for a divergence of $0.4^{\circ}$ by $1.05^{\circ}$. Isotherms are a $80,60,40$, and $20 \%$ of the peak temperature rise.

Figure 13. Evolution of the partial-energy component of the beam at distances of $100 \mathrm{~cm}, 500 \mathrm{~cm}$, and $1100 \mathrm{~cm}$ from the ion source for the line source model. Edge extraction and a divergence of $0.6^{\circ}$ perpendicular to the accelerator rails are assumed. 


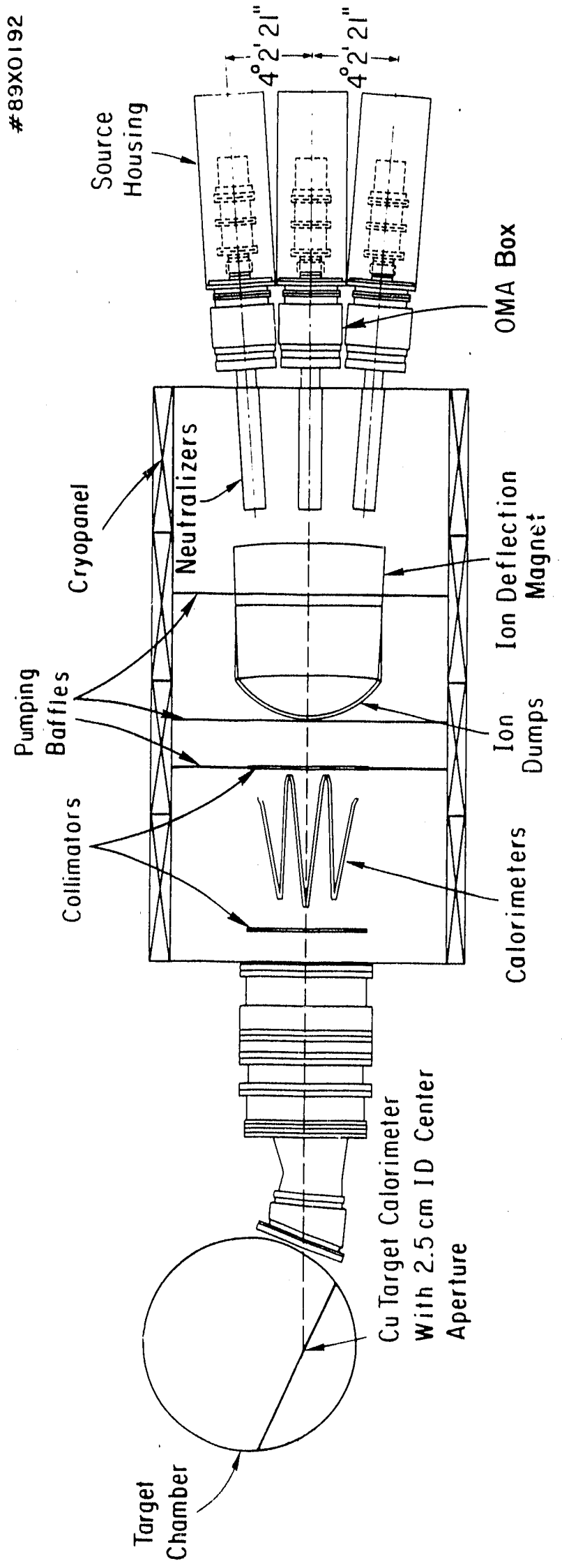




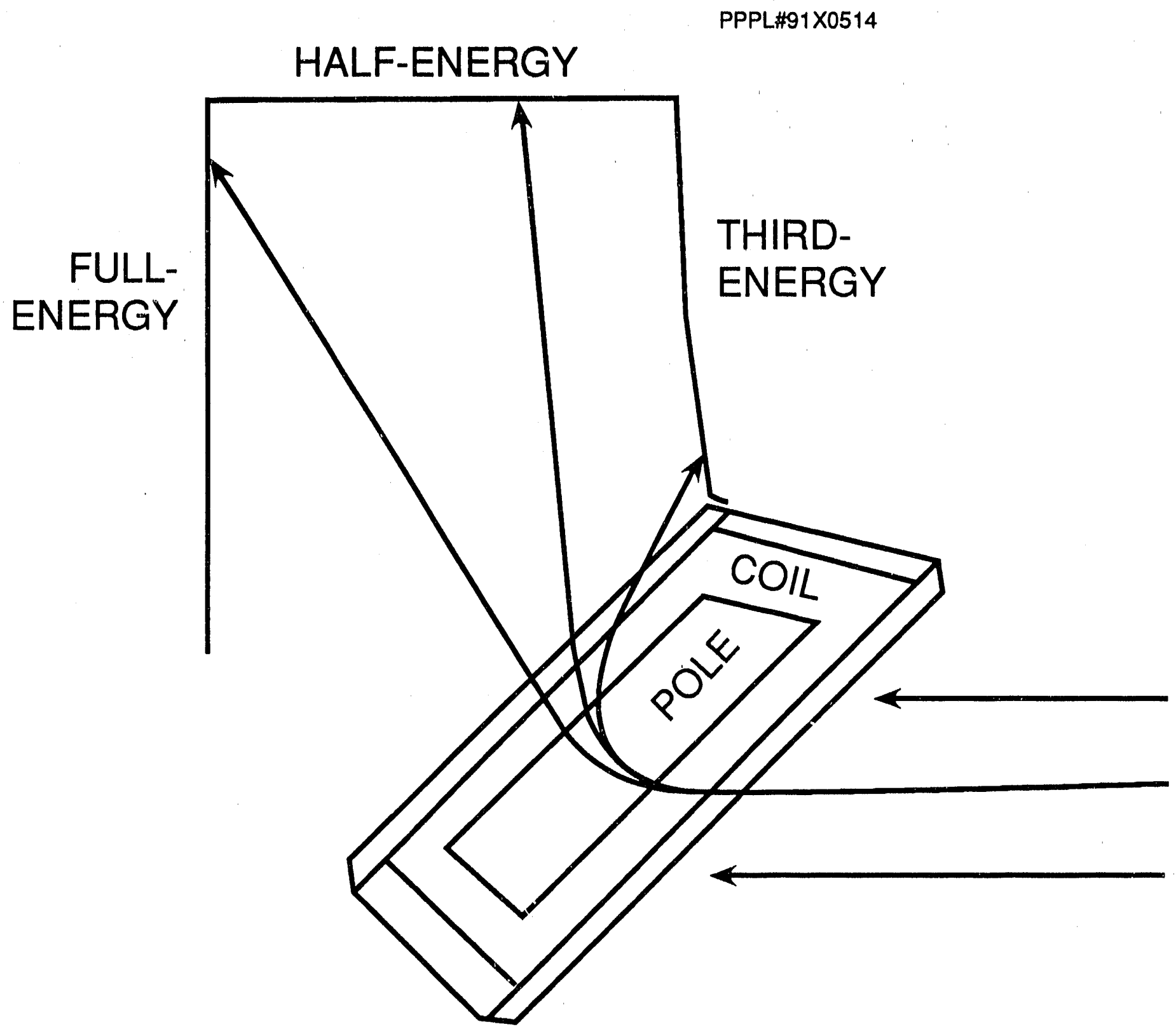

Fig. 2 


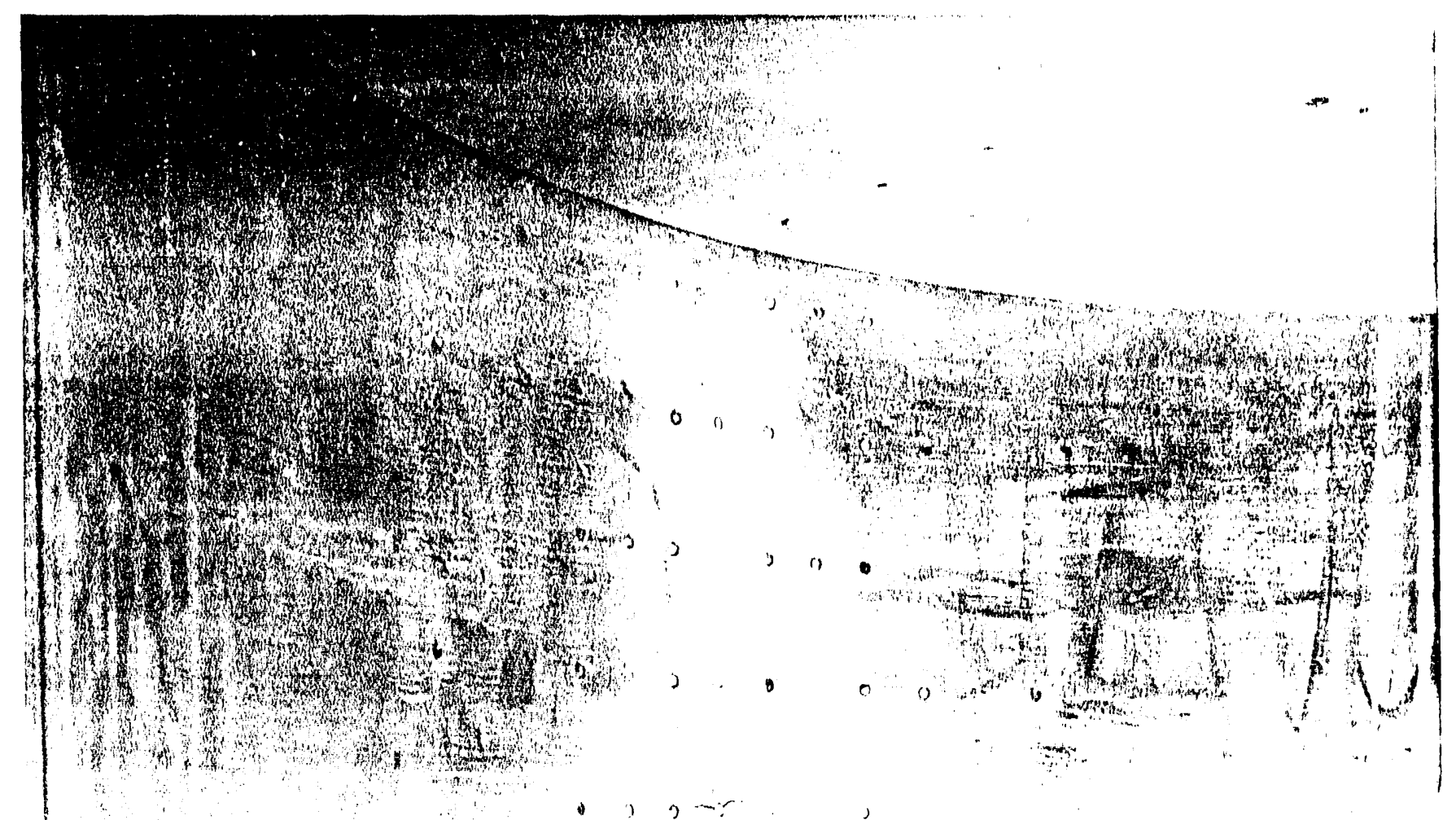




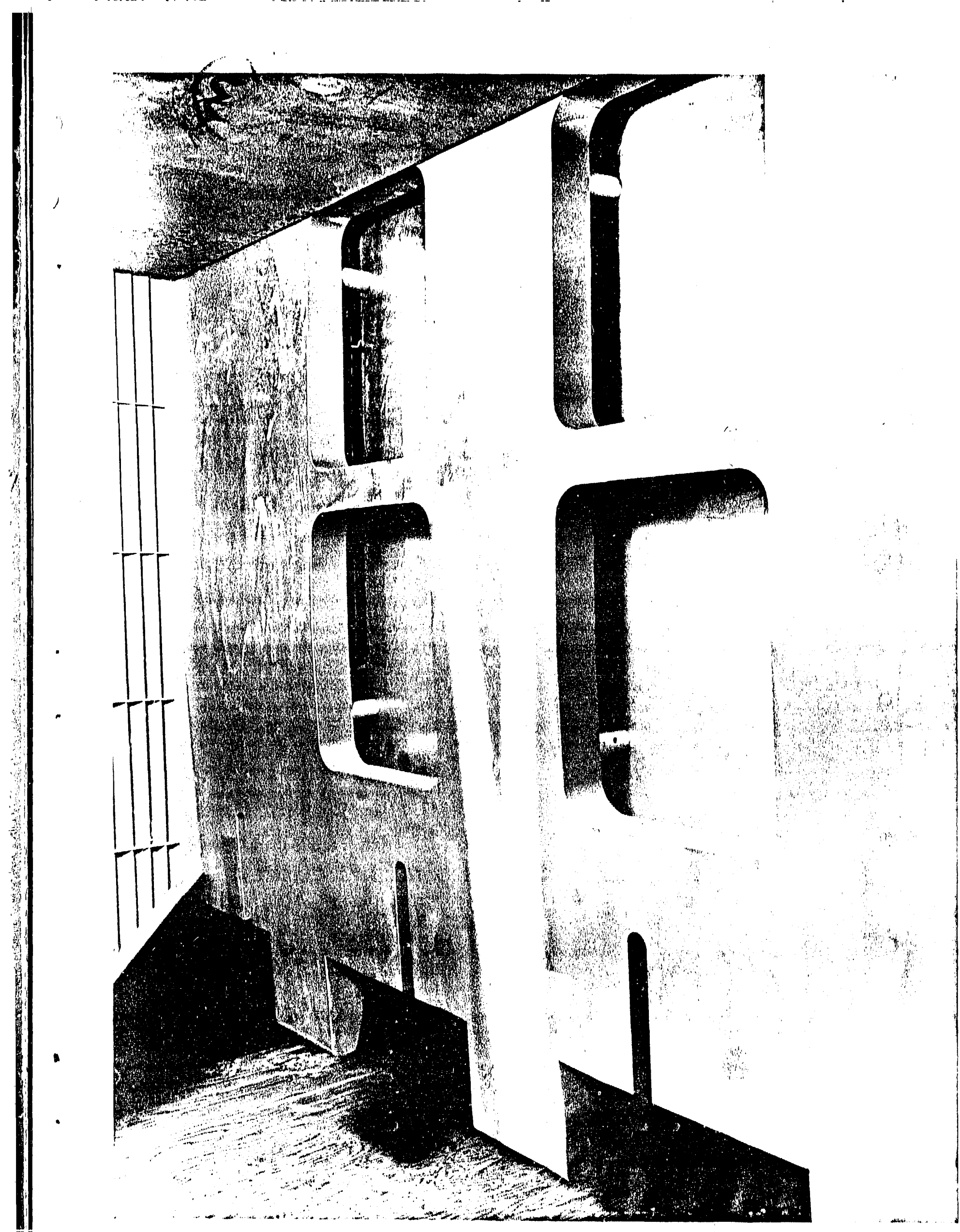

Fig. 4 
PPPL\#91X0512

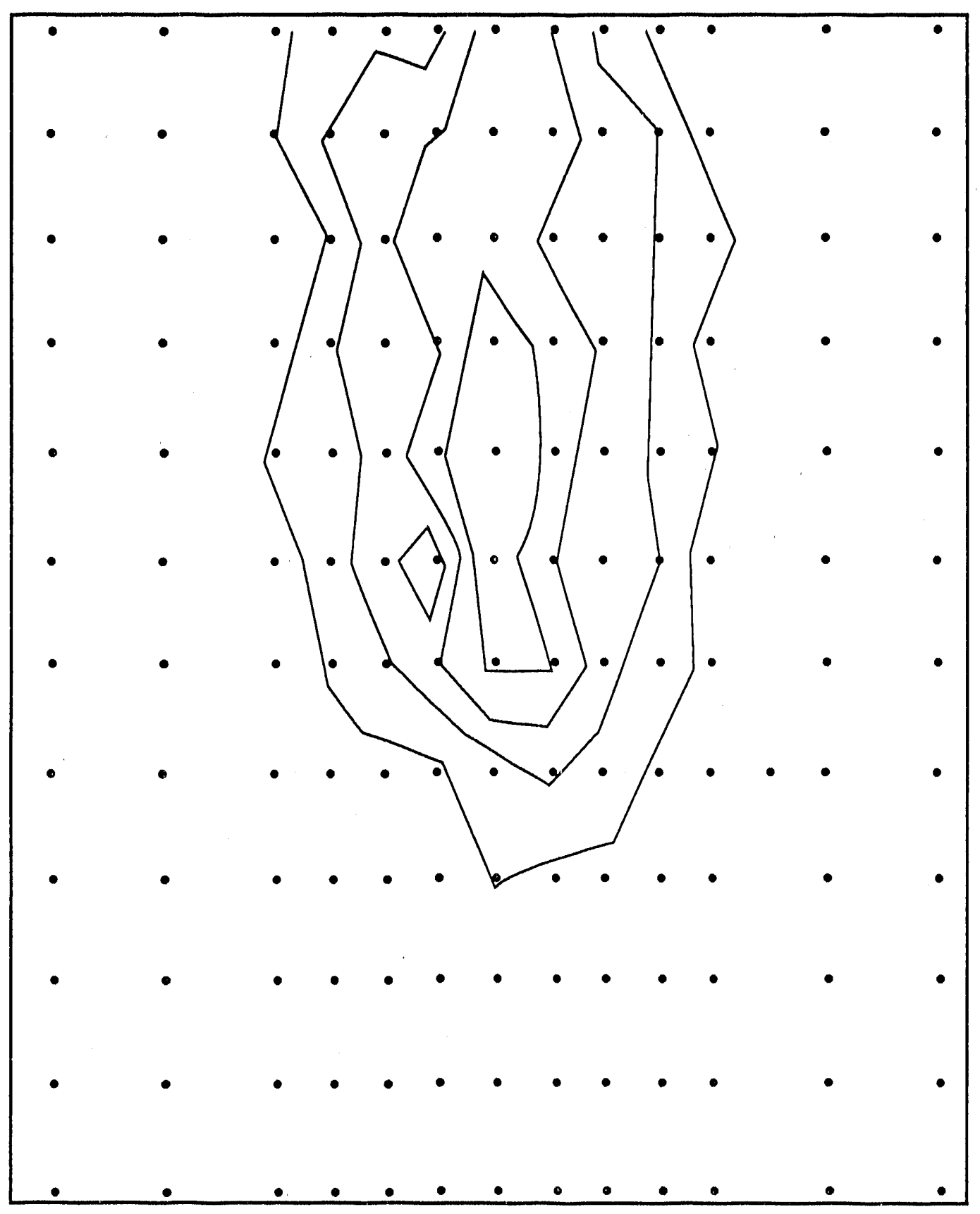

Fig. 5 


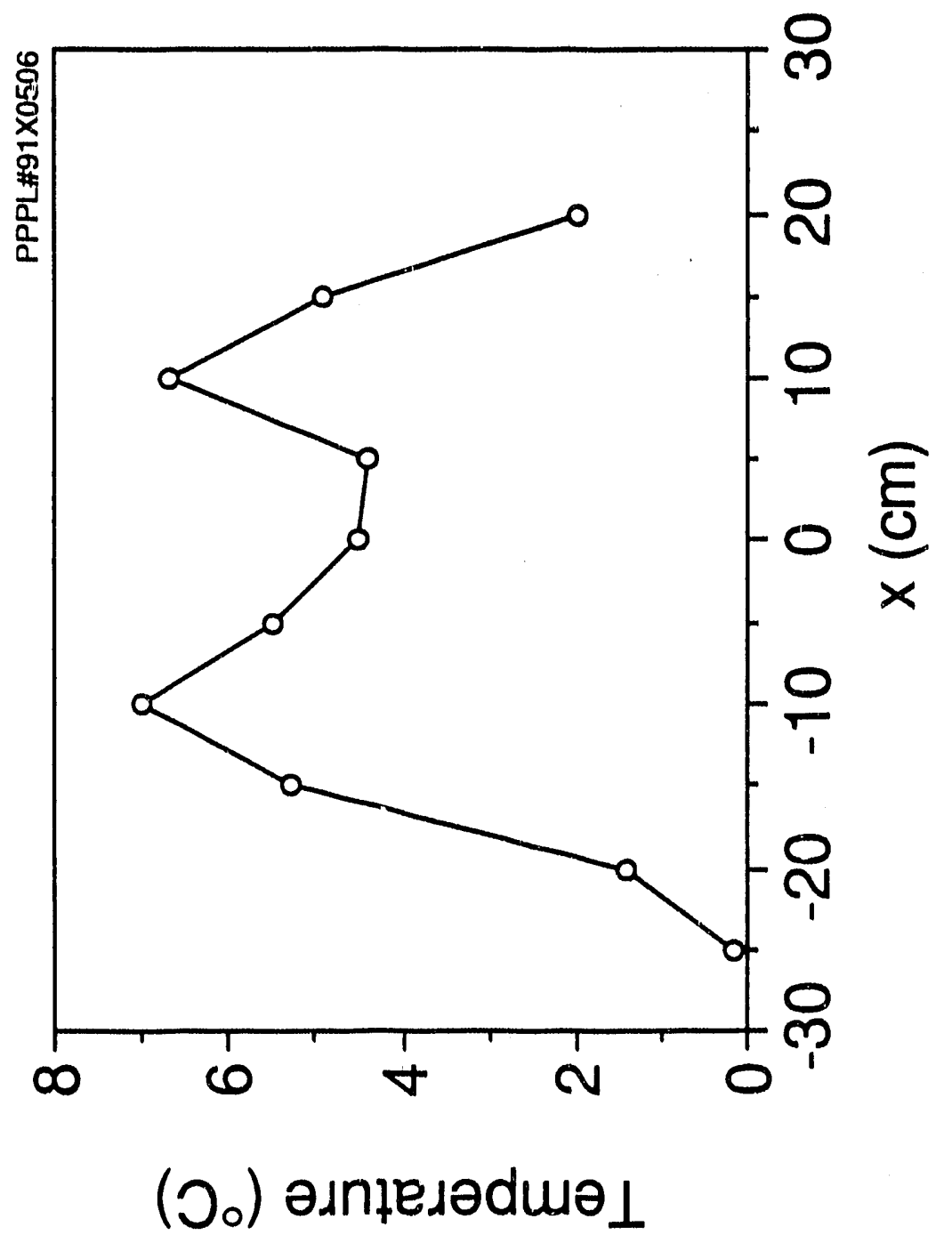

هin 


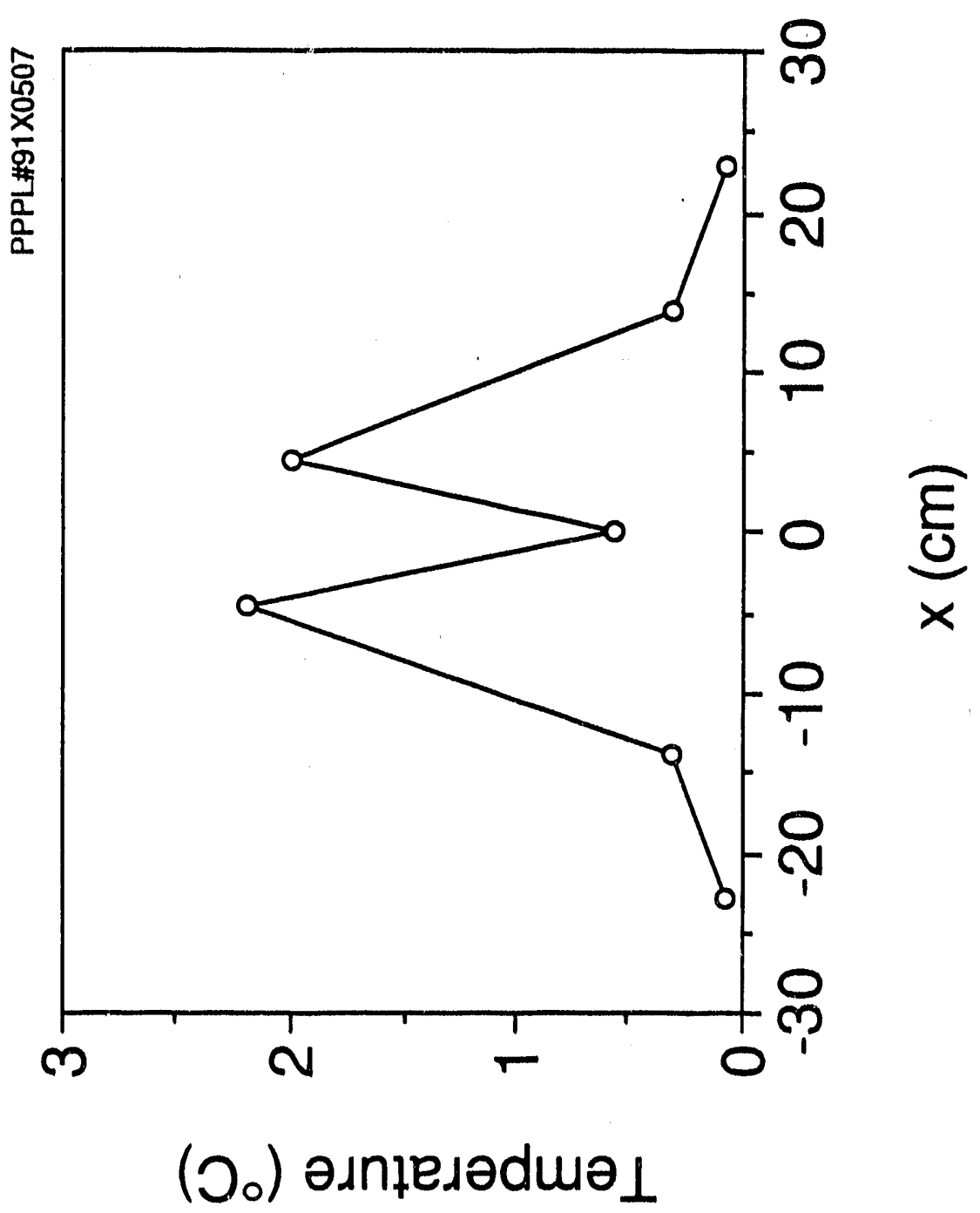

a 


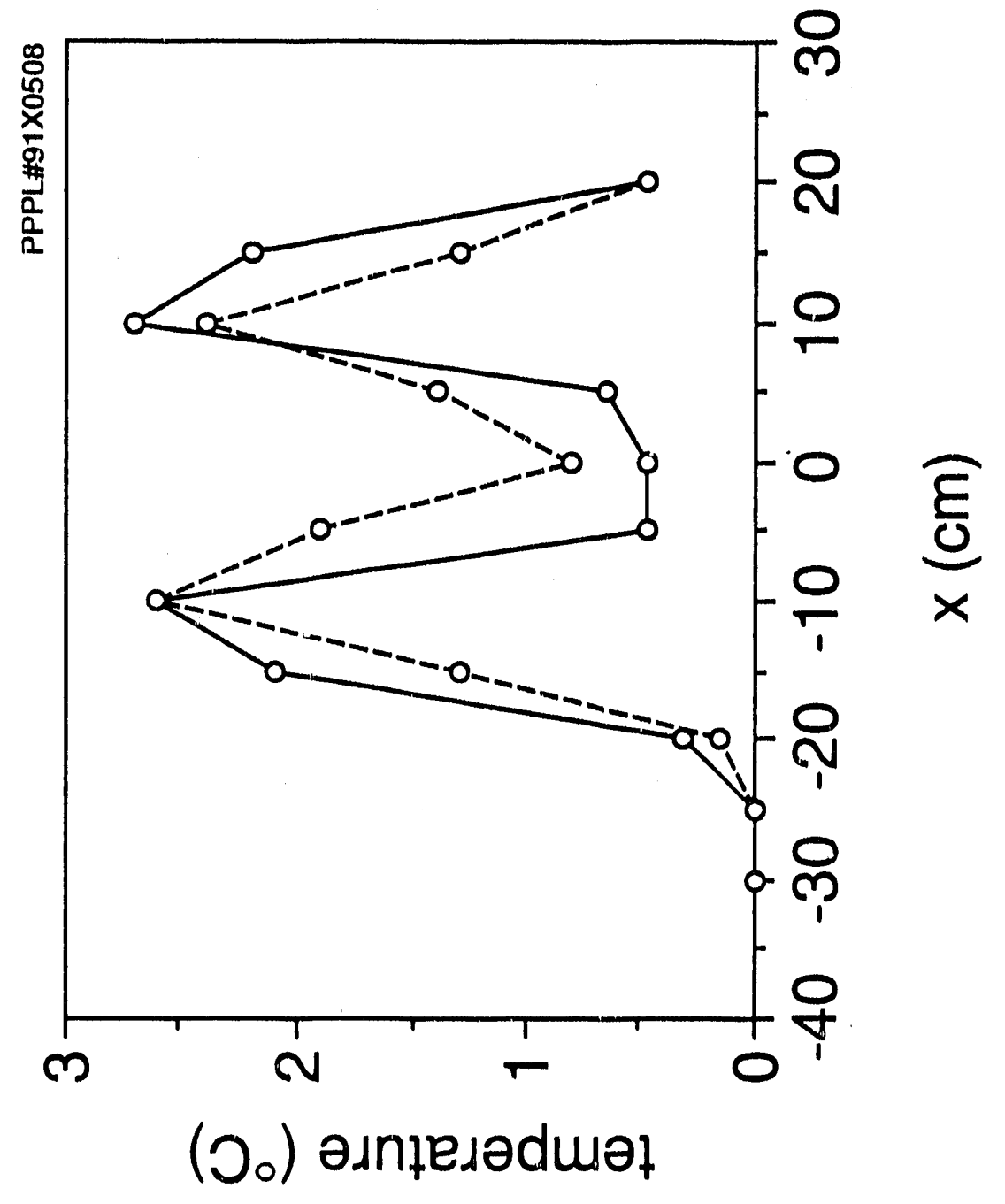

$\underset{\substack{\infty \\ \infty}}{\infty}$ 


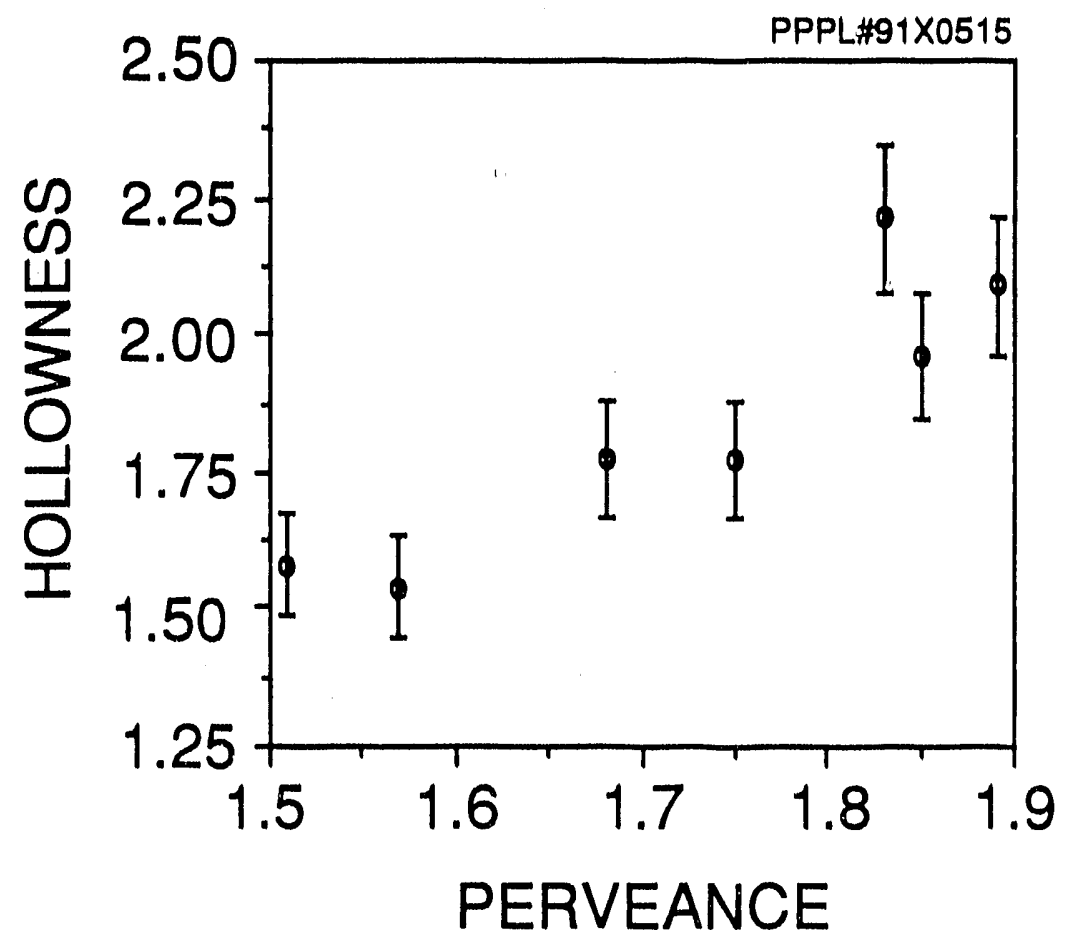

F1g. 9 


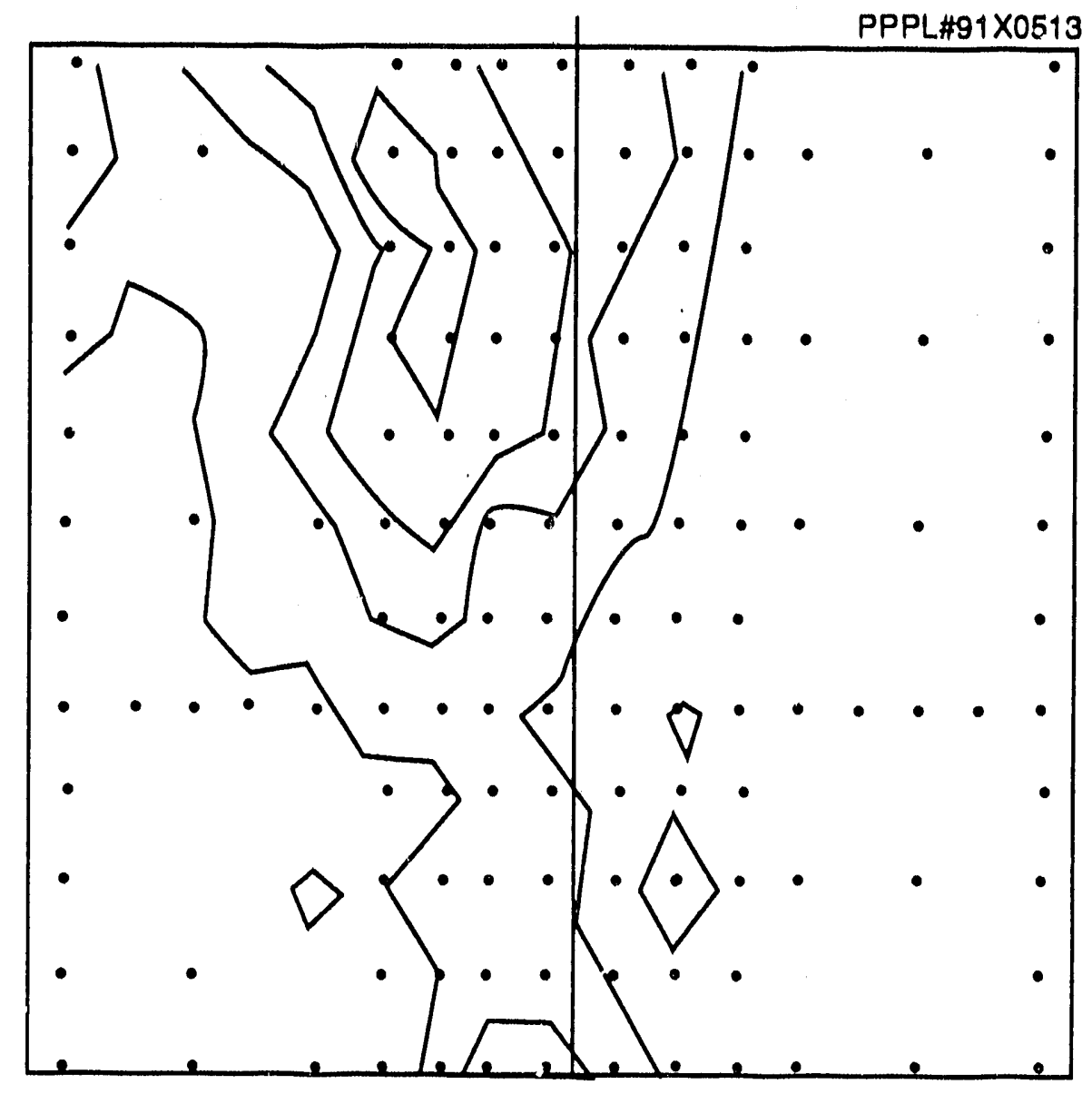

F1g. 10 


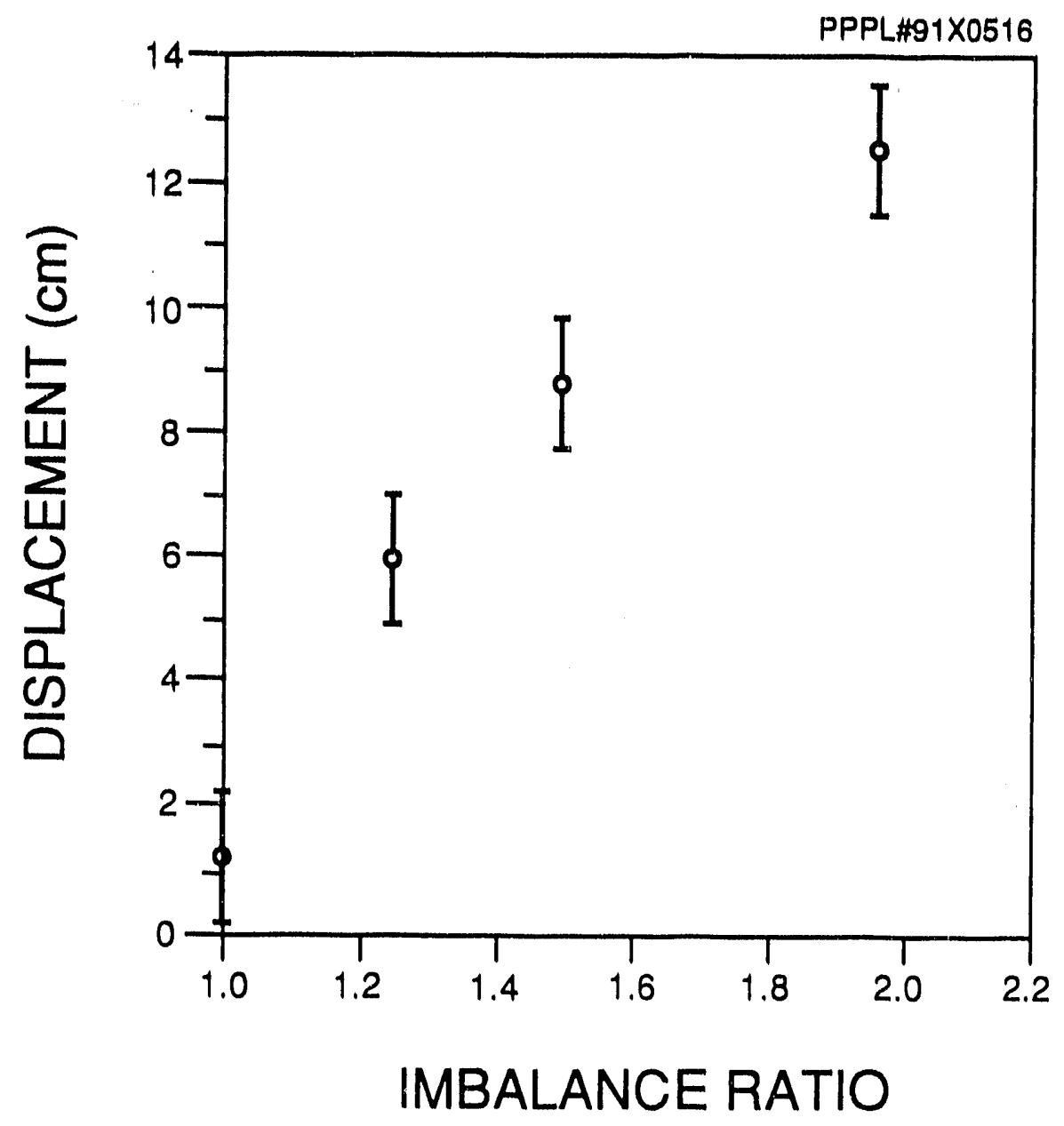

F1g. 11 


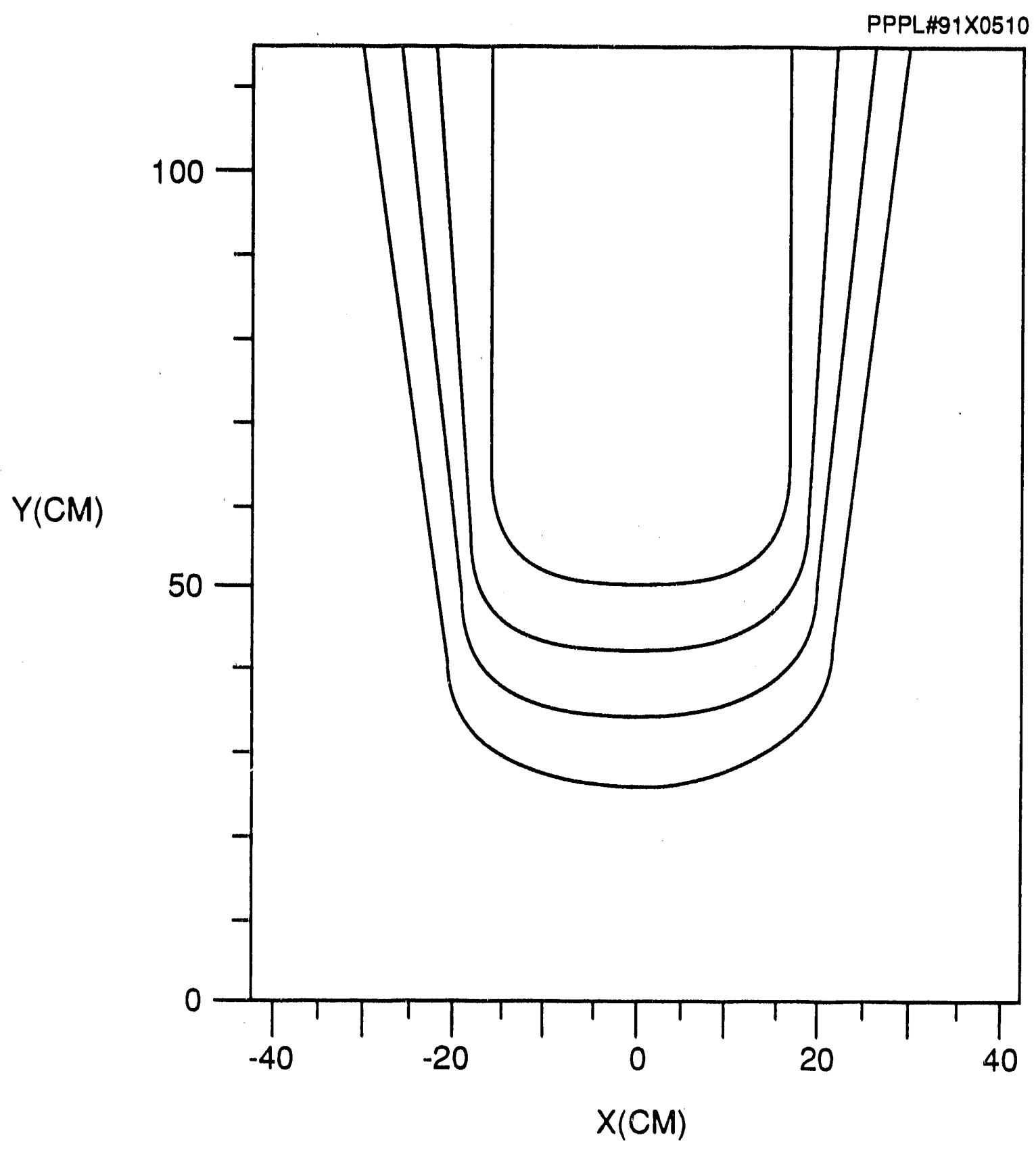

Fig. 12 


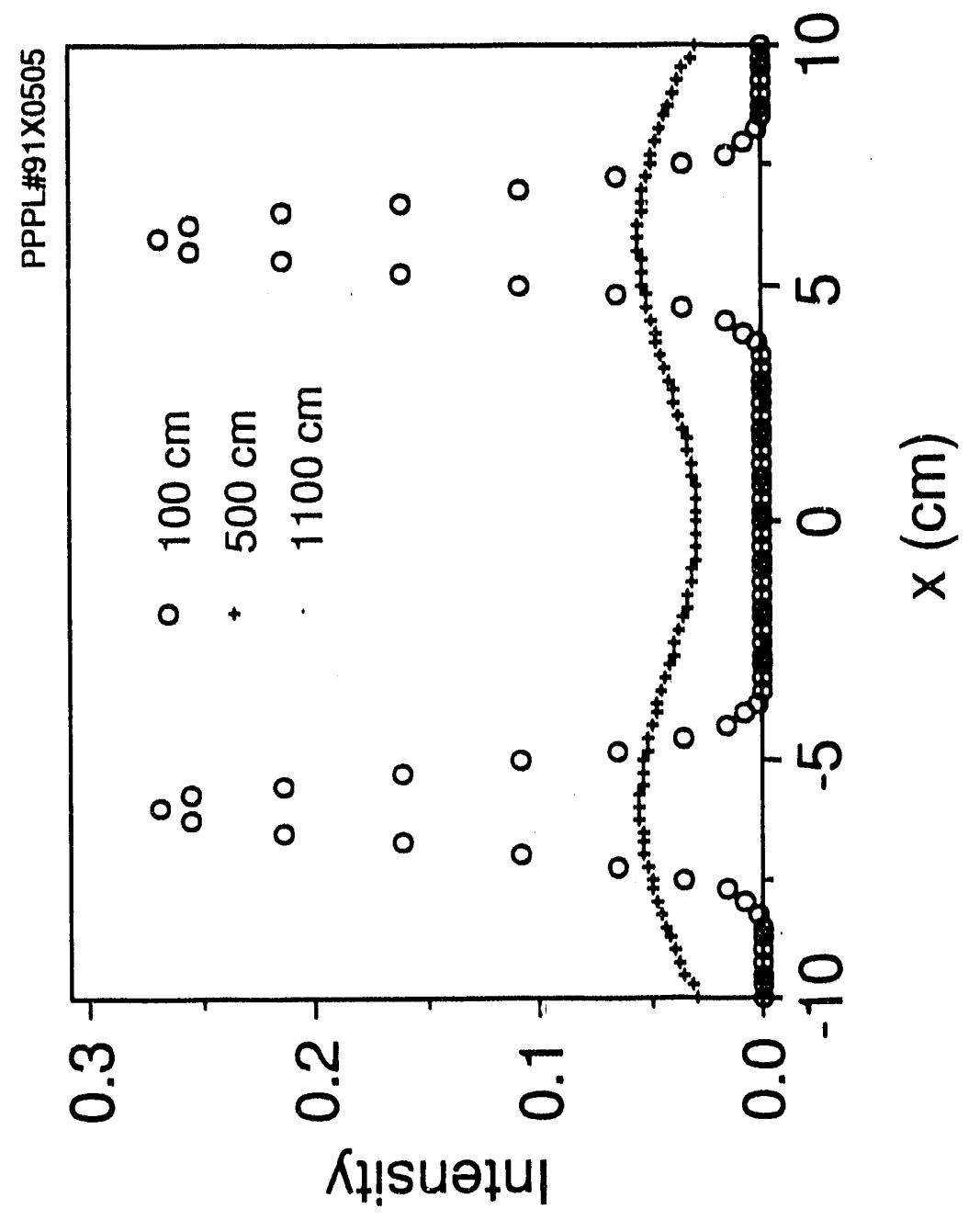




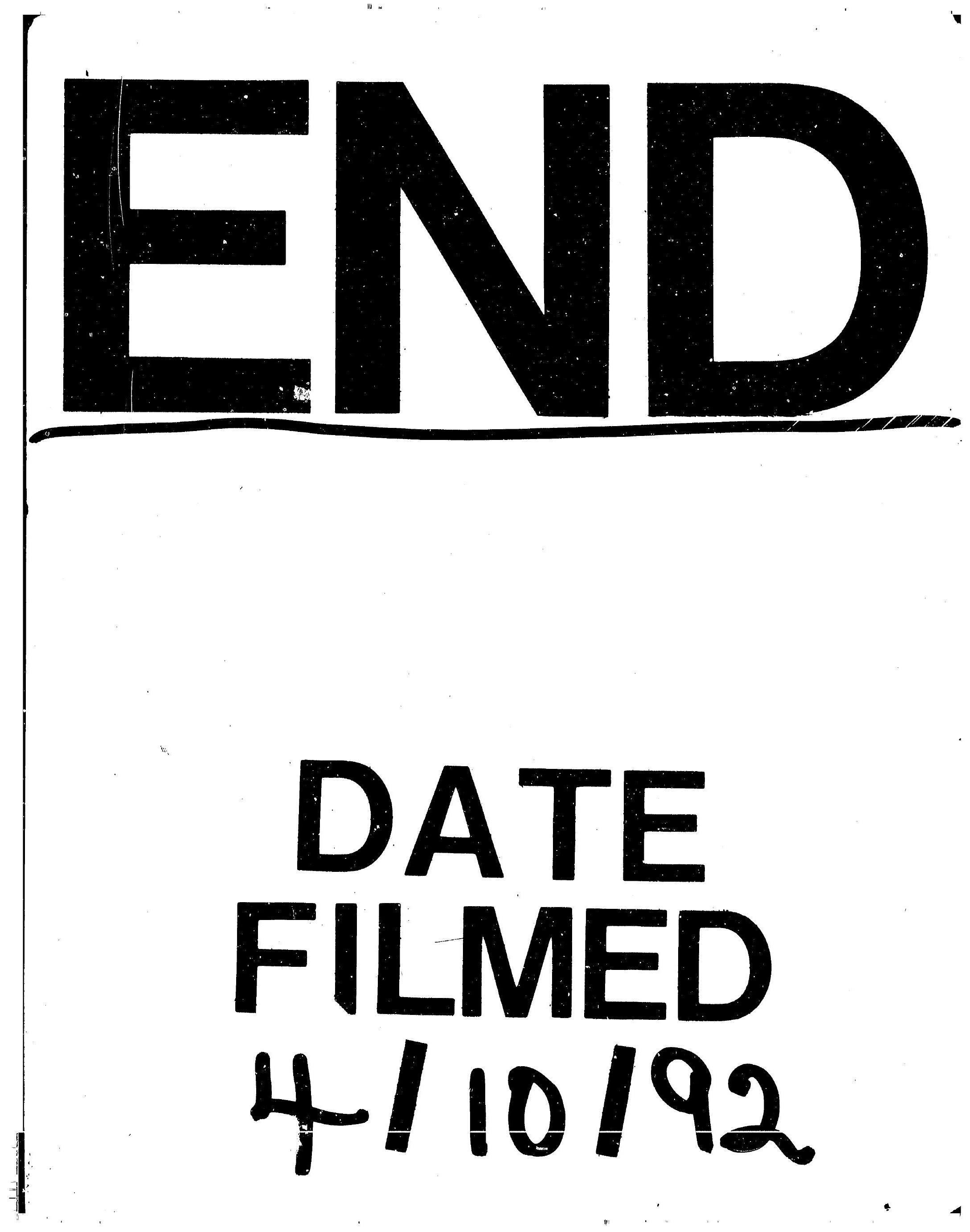




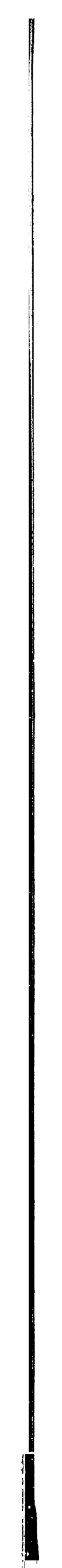

